\title{
ПОЛОВЫЕ ДИСПРОПОРЦИИ В ПОТОКАХ ДОЛГОВРЕМЕННОЙ МИГРАЦИИ В РОССИИ
}

\author{
НИКИТА МКРТЧЯН
}

\begin{abstract}
На основе данных Росстата проанализировано распределение потоков долговременной миграции в России по полу за 2004-2020 г2. с учетом их различий в отдельных возрастных группах. В международной миграции в России отмечается явное преобладание мужчин в трудоспособных возрастах, диспропорции нарастали после изменения методики учета в 2007 и особенно после 20112. Они привели не только к изменению масштабов учтенной долговременной миграции, но и к кардинальному изменению ее половозрастной структуры. $K$ кониу рассматриваемого периода диспропоричи сохранились, но масштаб их существенно уменьшился. Во внутристрановых переселениях в цуелом диспропорции полов не выражено, однако в молодых возрастах женщины более активны, особенно в потоке внутрирегиональной миграции. Изменение подходов к учету внутренних долговременных мигрантов в 2011 г., приведшее к изменению их возрастного профиля, практически не оказало воздействия на их распределение по полу. Предприняты попытки объяснения неравного участия мужчин и женщиин в миграции, однако эти особенности нуждаются в дальнейшем изучении. Ввиду существенной динамики половозрастного состава мигрантов ее необходимо своевременно учитывать при прогнозировании наряду с регулярными корректировками общих прогнозных гипотез.
\end{abstract}

Ключевые слова: миграџия населения, статистика миграции, международная миграция, внутристрановая миграция ,внутрирегиональная миграция, половозрастная структура мигрантов.

Структурные особенности миграции, имеющие ключевое значение для демографического развития России, изучены слабо. Но если возрастные аспекты миграции находят отражение в сравнительно немногочисленных публикациях (Карачурина, Мкртчян 2017), то распределению мигрантов по полу исследователи уделяют незаслуженно мало внимания. Между тем, как показывают статистические данные, соотношение полов в отдельных потоках миграции далеко от нормального, существует немало диспропорций, способных влиять на население как страны в целом, так и отдельных ее регионов.

Избирательность, селективность миграции по полу и возрасту как в международных (Belanger, Rahman 2013), так и во внутристрановых (Corbett 2007) потоках - имманентная ее особенность. Возникающие в связи с этим половозрастные диспропорции в населении отдельных территорий наиболее остры в развивающихся странах, находящихся на пути урбанистического развития и переживающих бурный рост городов в результате миграции из сельской местности (Rodriguez-Vignoli, Rowe 2018), и странах, принимающих большие потоки международных мигрантов. Так, сразу после воссоединения Германии отток молодых женщин из восточных земель в западные вызвал серьезный их дефицит, особенно в сельских общинах (Krohnert, Vollmer 2012). Отток женщин из сельской местности ставит под угрозу устойчивость местных сообществ (Martin 2009).

НИКИТА ВЛАДИМИРОВИч МКРТЧЯН (nmkrtchyan@hse.ru), НАЦИОНАЛЬНЫЙ ИССЛЕДОВАТЕЛЬСКИЙ УНИВЕРСИТЕТ «ВЫСШАЯ ШКОЛА ЭКОНОМИКИ», РОССИЙСКАЯ АКАДЕМИЯ НАРОДНОГО ХОЗЯЙСТВА И ГОСУДАРСТВЕННОЙ СЛУЖБЫ ПРИ ПРЕЗИДЕНТЕ РОССИЙСКОЙ ФЕДЕРАЦИИ, РОССИЯ.

СТАТЬЯ ПОДГОТОВЛЕНА В РАМКАХ ВЫПОЛНЕНИЯ НАУЧНО-ИССЛЕДОВАТЕЛЬСКОЙ РАБОТЫ ГОСУДАРСТВЕННОГО ЗАДАНИЯ РАНХИГС.

СТАТЬЯ ПОСТУПИЛА В РЕДАКЦИЮ В ИЮЛЕ 2021 Г. 
Цель данной статьи - рассмотрение самых общих особенностей распределения долговременных международных и внутренних мигрантов в России по полу, в том числе в отдельных возрастных группах. Анализируются данные Росстата за 2004-2020 гг., принимаются во внимание изменения методики учета миграции в рассматриваемые годы. В России, как и во многих странах, соотношение полов численно смещено в пользу женщин. Это обеспечивается, прежде всего, разницей в смертности мужчин и женщин, благодаря которой численное преимущество мужчин среди детей и молодежи уже в средних возрастах сменяется преобладанием женщин. В России женщин становится больше уже к возрасту 30 с небольшим лет, диспропорции полов выравниваются крайне медленно, а в отдельных возрастах даже нарастают (Вишневский 2013). И это несмотря на то, что последствия Второй мировой войны, определившие острейшие диспропорции в соотношении полов в пожилых возрастах в конце XX века, к настоящему времени уже не оказывают на него существенного влияния.

В целом в долговременной миграции также преобладают женщины, что связано, прежде всего, с их общим преобладанием в населении. Однако, как показывают самые нехитрые расчеты, соотношение полов в миграции не имеет линейной связи с их долей в населении, а в отдельных потоках оно меняется в пользу мужчин, эти изменения происходят скачкообразно (таблица 1). Особенно сильные диспропорции отмечены в международной миграции.

Таблица 1. Соотношение полов в населении России и в миграционных потоках, число мужчин на 1000 женщин, 2004-2020

\begin{tabular}{|c|c|c|c|c|c|c|c|c|}
\hline \multirow{3}{*}{ Год } & \multirow{3}{*}{$\begin{array}{c}\text { Население } \\
\text { России на } \\
\text { начало } \\
\text { года }\end{array}$} & \multicolumn{7}{|c|}{ Миграция } \\
\hline & & \multirow[t]{2}{*}{ всего } & \multicolumn{3}{|c|}{ в пределах России } & \multicolumn{3}{|c|}{ международная } \\
\hline & & & всего & $\begin{array}{c}\text { внутри- } \\
\text { региональная }\end{array}$ & $\begin{array}{c}\text { меж- } \\
\text { региональная }\end{array}$ & оборот & прибытия & выбытия \\
\hline 2004 & 866,6 & 891,5 & 893,5 & 848,0 & 958,4 & 872,4 & 862,7 & 887,0 \\
\hline 2005 & 863,4 & 865,9 & 869,2 & 824,3 & 933,0 & 841,2 & 826,4 & 879,9 \\
\hline 2006 & 860,9 & 870,2 & 868,2 & 824,5 & 928,5 & 885,8 & 892,5 & 863,1 \\
\hline 2007 & 859,7 & 887,9 & 867,0 & 822,3 & 929,5 & 1023,2 & 1059,2 & 827,9 \\
\hline 2008 & 859,3 & 895,2 & 872,1 & 828,9 & 928,7 & 1047,3 & 1077,3 & 856,5 \\
\hline 2009 & 859,3 & 918,9 & 885,9 & 838,2 & 947,8 & 1122,2 & 1155,5 & 872,6 \\
\hline 2010 & 859,6 & 887,8 & 859,6 & 815,0 & 915,4 & 1166,8 & 1228,1 & 872,9 \\
\hline 2011 & 860,3 & 936,5 & 881,4 & 829,5 & 951,2 & 1508,6 & 1574,9 & 1007,2 \\
\hline 2012 & 861,3 & 964,6 & 883,7 & 831,8 & 947,2 & 1808,9 & 1683,0 & 2342,9 \\
\hline 2013 & 862,4 & 988,6 & 886,9 & 836,2 & 945,9 & 1941,4 & 1757,8 & 2553,4 \\
\hline 2014 & 863,1 & 992,5 & 870,3 & 827,9 & 916,7 & 1839,2 & 1634,0 & 2325,0 \\
\hline 2015 & 863,3 & 965,3 & 870,3 & 832,4 & 909,2 & 1522,4 & 1253,4 & 2162,2 \\
\hline 2016 & 863,6 & 939,5 & 875,0 & 837,6 & 913,1 & 1308,4 & 1223,5 & 1482,3 \\
\hline 2017 & 864,4 & 942,6 & 874,3 & 836,5 & 910,5 & 1306,4 & 1293,8 & 1326,3 \\
\hline 2018 & 865,2 & 937,2 & 868,9 & 834,4 & 901,1 & 1300,2 & 1261,6 & 1351,7 \\
\hline 2019 & 865,9 & 962,2 & 877,9 & 851,6 & 903,2 & 1343,2 & 1341,9 & 1345,5 \\
\hline 2020 & 866,3 & 962,3 & 866,7 & 837,6 & 893,9 & 1355,7 & 1271,1 & 1467,7 \\
\hline
\end{tabular}

Источник: Расчеты автора по данным Росстата. 
Уже Всероссийская перепись населения 2002 г. показала, что в крупных городах (прежде всего, Москве) резко нарушены половые пропорции в пользу мужчин в отдельных этнических группах - азербайджанцев, узбеков, грузин, армян (Зайончковская 2009). Однако эта миграция оставалась в основном невидимой для текущего учета, он не охватывал многих мигрантов, де-факто длительное время проживающих на территории России.

Первое значительное изменение соотношения мужчин и женщин в регистрируемых потоках миграции связано с резким увеличением доли мужчин в потоке прибывших международных мигрантов в 2007 г. Именно в данном году произошло изменение системы учета миграции: как прибывших (долговременных) мигрантов стали учитывать тех, кто впервые получил разрешение на временное пребывание в России. До этого учету подлежали только те, кто получал регистрацию по месту жительства; по мнению экспертов, учет миграции в эти годы находился в критическом состоянии (Чудиновских 2004). Действовавшая с 2007 г. система учета международной миграции не решала данной проблемы полностью, но, по-видимому, позволила вовлечь в статистическую разработку значительные контингенты долговременных мигрантов и в определенной мере приблизить их учет к реальности.

Таблица 2. Соотношение полов в потоке международной миграции в 2000-е годы, прибытия, число мужчин на 1000 женщин

\begin{tabular}{l|r|r}
\hline & $2004-2006$ & $2007-2010$ \\
\hline Международная миграция - всего & 860,5 & 1119,3 \\
страны СНГ и Балтии & 847,1 & 1104,0 \\
Азербайджан & 1223,1 & 1774,7 \\
Армения & 1028,6 & 1144,1 \\
Белоруссия & 820,3 & 898,1 \\
Грузия & 876,5 & 978,8 \\
Казахстан & 799,7 & 874,4 \\
Киргизия & 865,6 & 950,7 \\
Латвия & 784,6 & 982,0 \\
Литва & 903,9 & 1059,5 \\
Молдавия & 985,5 & 1094,0 \\
Таджикистан & 1306,1 & 2800,5 \\
Туркмения & 738,9 & 855,1 \\
Узбекистан & 822,9 & 1088,1 \\
Украина & 753,5 & 833,7 \\
Эстония & 1076,3 & 1010,2 \\
страны дальнего зарубежья & 1200,5 & 1548,8 \\
\hline
\end{tabular}

Источник: Расчеты автора по данным Росстата.

Динамика прибытий мигрантов по странам в 2007 г. в сравнении с предшествующими годами показала, что наиболее существенно увеличение числа и доли мужчин в потоке обеспечили страны Закавказья (но Грузия - только в 2007 г., уже с 2008 г. число мигрантов из этой страны после событий в Южной Осетии и последовавшего за тем резкого ухудшения межгосударственных отношений России и Грузии стало снижаться), Таджикистан, Узбекистан и Киргизия. Именно из этих стран во второй половине 
2000-х годов нарастал поток временных трудовых мигрантов в Россию. Увеличился приток также из Украины, которая постоянно являлась основным миграционным донором России.

В целом после 2007 г. в потоке прибытий в Россию долговременных международных мигрантов мужчины стали преобладать. Но если рассматривать основные страны миграционные доноры России, к которым относятся, прежде всего, постсоветские, наиболее сильно диспропорции затронули поток из Таджикистана и Азербайджана (таблица 2), в меньшей мере - из Армении и Узбекистана. Среди стран дальнего зарубежья наиболее значимый перевес мужчин был отмечен в потоке постоянной миграции из Китая. В традиционных обществах, значительная роль которых по-прежнему сильна в ряде постсоветских стран, женщина по-прежнему не так самостоятельна, как мужчина, что выражается в их меньшей вовлеченности в процессы международной миграции (Тюрюканова 2011).

Соотношение полов имеет выраженную возрастную специфику, население разных возрастов участвует в миграции с разной интенсивностью. Изменение пропорций мужчин и женщин в потоке международной миграции по-разному затронуло отдельные возрастные группы, в наибольшей мере преобладание мужчин после 2007 г. было отмечено в молодых и средних трудоспособных возрастах (рисунок 1). При этом в потоке прибывших из Таджикистана в возрасте 20-24 лет мужчин было больше, чем женщин, в 4,4 раза, в 25-29 лет - в 4,3 раза. Для миграции из Украины и Казахстана при общем увеличении доли мужчин в потоке таких резких диспропорций не отмечалось. В потоке прибывших из стран дальнего зарубежья, а также стран Балтии мужчины наиболее явно преобладали в возрастах 40-49 лет. В этом возрасте в Россию чаще приезжали высококвалифицированные трудовые мигранты, и не всегда в составе семей. Впрочем, этот миграционный поток в Россию даже в «нулевые» годы был невелик и в значительной мере латентен, т. е. не учитывался в статистике долговременной миграции.

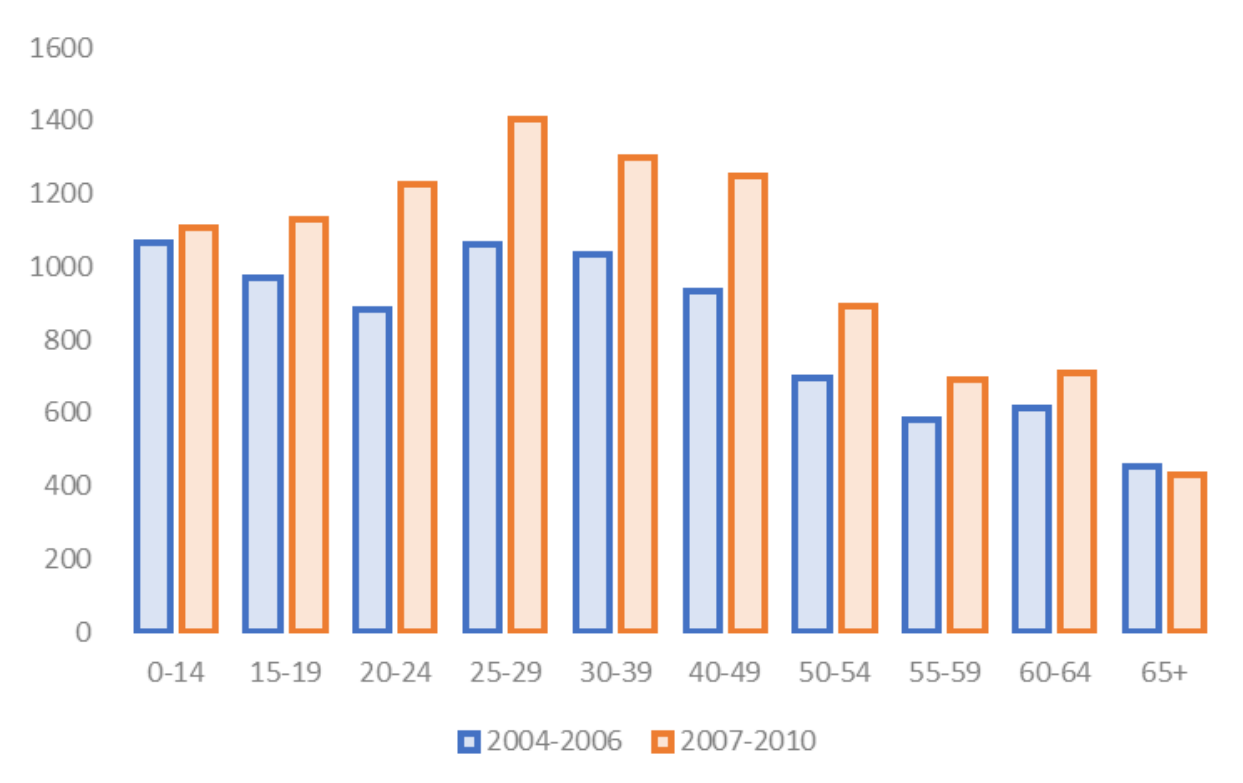

Рисунок 1. Соотношение полов в потоке международной миграции по отдельным возрастным группам, прибытия, число мужчин на 1000 женщин

Источник: Расчеты автора по данным Росстата. 
Получается, что уже в конце 2000-х годов половозрастное распределение международных мигрантов в России изменилось. Сбалансированная половозрастная структура, свойственная семейной и репатриационной миграции, претерпела серьезные изменения. Уже не в скрытом, а в явном виде сформировалась новая структура миграции с явным преобладанием в ней мужчин молодых возрастов, но все же не таким явным, как во временной трудовой миграции в те годы (Тюрюканова 2011).

Коренной пересмотр методики статистического учета миграции в России в 2011 г., затронувший как международную, так и внутристрановую миграцию, привел к дальнейшему изменению соотношений полов мигрантов. Напомним, что с 2011 г. как долговременных стали учитывать не только тех, кто получал регистрацию по месту жительства, но и регистрирующихся по месту пребывания на срок 9 месяцев и более. Как только срок постановки на учет подходит к концу, мигрант автоматически считается выбывшим к месту постоянного проживания. Применительно к международной миграции - в страну, откуда он прибыл, где до этого времени постоянно проживал, даже если он переселяется в пределах России.

Формально с учетом того, что отдельные категории мигрантов могли до 90 суток законно пребывать в России без оформления регистрации, новый критерий стал близко соответствовать рекомендациям ООН о долговременном пребывании в новом месте жительства 1 год и более. Несмотря на обоснованную критику новой методики, искажающей как реальные объемы долговременной миграции (Чудиновских 2019), так и отдельные структурные характеристики мигрантов (уровень образования, причины миграции и др.) (Мкртчян 2020), она позволяет получить представление о ранее латентных или полулатентных категориях мигрантов, например о перемещающихся в связи с получением высшего образования (Кашницкий 2017), а также об общих масштабах миграции. Неизменные характеристики мигрантов, к которым относится пол, а также те, которые могут быть автоматически пересчитаны (возраст), новая методика не искажает.

Особенность новой методики учета в том, что масштабы и характеристики прибытий она поменяла сразу же, а изменение характеристик выбытий произошло с временным лагом. Только в конце 2011 г. появились первые лица, у которых закончился срок регистрации по месту пребывания, полностью по-новому система заработала к середине 2010-х годов. Отсюда - лаг запаздывания динамики структурных характеристик миграционных потоков.

Как говорилось выше, соотношение полов прибывших международных мигрантов поменялось уже к 2010 г., но после реформы 2011 г. диспропорции резко увеличились, особенно в самых молодых трудоспособных возрастах (рисунок 2). Диспропорции полов выбывших начали меняться только после 2011 г., но были более резкими, чем у прибывших. В потоке прибывших к 2015 г. доля зарегистрированных по месту жительства (по старой методике) составляла 28\%, тогда как в потоке выбывших - только 6\%. К сожалению, данные Росстата не позволяют оценить половозрастную структуру международных мигрантов по старой и новой методике отдельно. Но из приведенных цифр видно, что новая система учета затронула хоть и большую часть, но не все прибытия, а поток выбывших 
практически полностью стал формироваться за счет тех, у кого закончилась временная (по месту пребывания) регистрация.

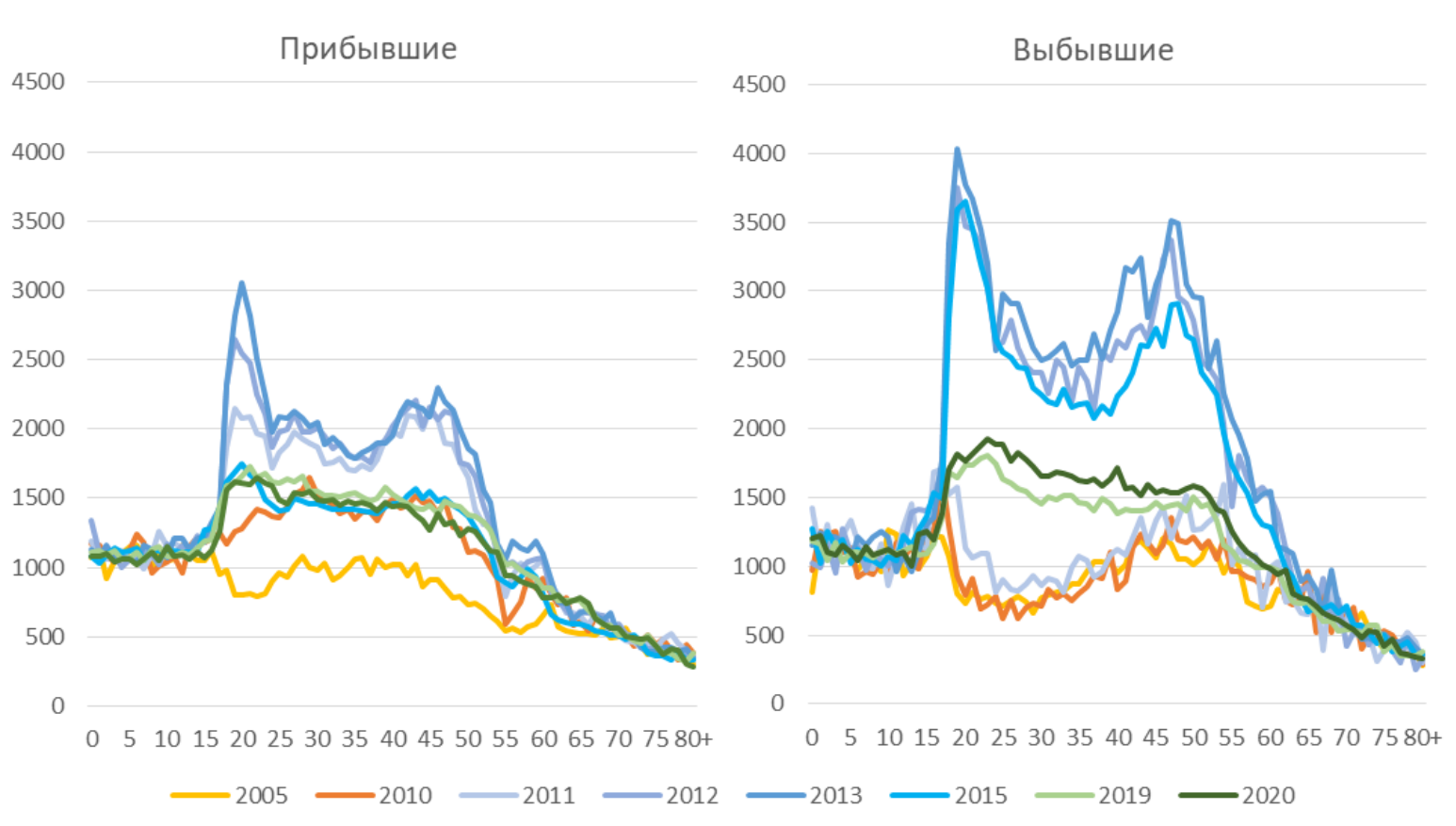

Рисунок 2. Соотношение полов в потоке международной миграции по 1-летним возрастным группам, число мужчин на 1000 женщин

Источник: Расчеты автора по данным Росстата.

Также на рисунке 2 видно, что во второй половине 2010-х годов диспропорции полов как прибывших, так и выбывших существенно сгладились. На это оказало влияние:

1. изменение структуры стран - основных миграционных доноров России. Снижение роли стран Средней Азии в долговременной миграции компенсировалось увеличением миграции из Украины, в потоке которой не было таких сильных диспропорций полов;

2. увеличение в структуре долговременной миграции репатриационной составляющей, стимулированной участием в Госпрограмме содействия переселению в Россию зарубежных соотечественников и членов их семей. Это вновь усилило роль семейной миграции, которая частично заместила миграцию одиночек, чаще всего представленных мужчинами;

3. резкое снижение диспропорций полов среди прибывших в молодых и средних возрастах из всех стран - основных миграционных доноров России. Причины этих изменений непонятны, вернее будет сказать, что мы не знаем причин столь резкого и синхронного обострения диспропорций полов среди прибывших международных мигрантов в начале 2010-х годов. Возможно, это связано с тем, что у мужчинмигрантов было больше стимулов оформлять регистрацию по месту пребывания на срок 9 месяцев и более, в то время как женщины либо обходились краткосрочной регистрацией, либо не оформляли регистрации совсем. Более частая регистрация мужчин-мигрантов могла быть связана с меньшей толерантностью к ним со стороны правоохранительных органов. 
Резкое преобладание мужчин в потоке международной миграции начала 2010-х годов затеняет современные диспропорции полов, которые в трудоспособных возрастах достигают 1,5-2 раз. Международная миграция «подпитывает» население России преимущественно мужчинами, что приносит в кратко- и среднесрочной перспективе экономические выгоды, но менее ценно с позиций демографического развития.

Во внутристрановой миграџии нет такого выраженного, как в международной, преобладания мужчин в потоках. В возрастах, когда диспропорции полов в населении еще не достигают существенных значений, на 1000 женщин, участвующих в миграции, вплоть до последних лет приходилось 600-1250 мужчин (рисунок 3). Новая методика учета миграции в 2011 г. (изменения 2007 г. внутристрановой миграции не касались) не привела в 2011-2012 гг. к резкому, как это было в международной миграции, изменению соотношения полов ни в целом в потоке, ни в отдельных возрастах. Значимое преобладание мужчин в средних возрастах во внутрироссийской миграции сошло на нет к концу 2010-х годов, когда методика учета миграции не претерпевала изменений. В случае международной миграции диспропорции обострились именно в первые пореформенные годы, во внутренней миграции изменений в соотношении мужчин и женщин, участвующих в миграции в отдельных возрастах в 2011-2012 гг., не произошло.

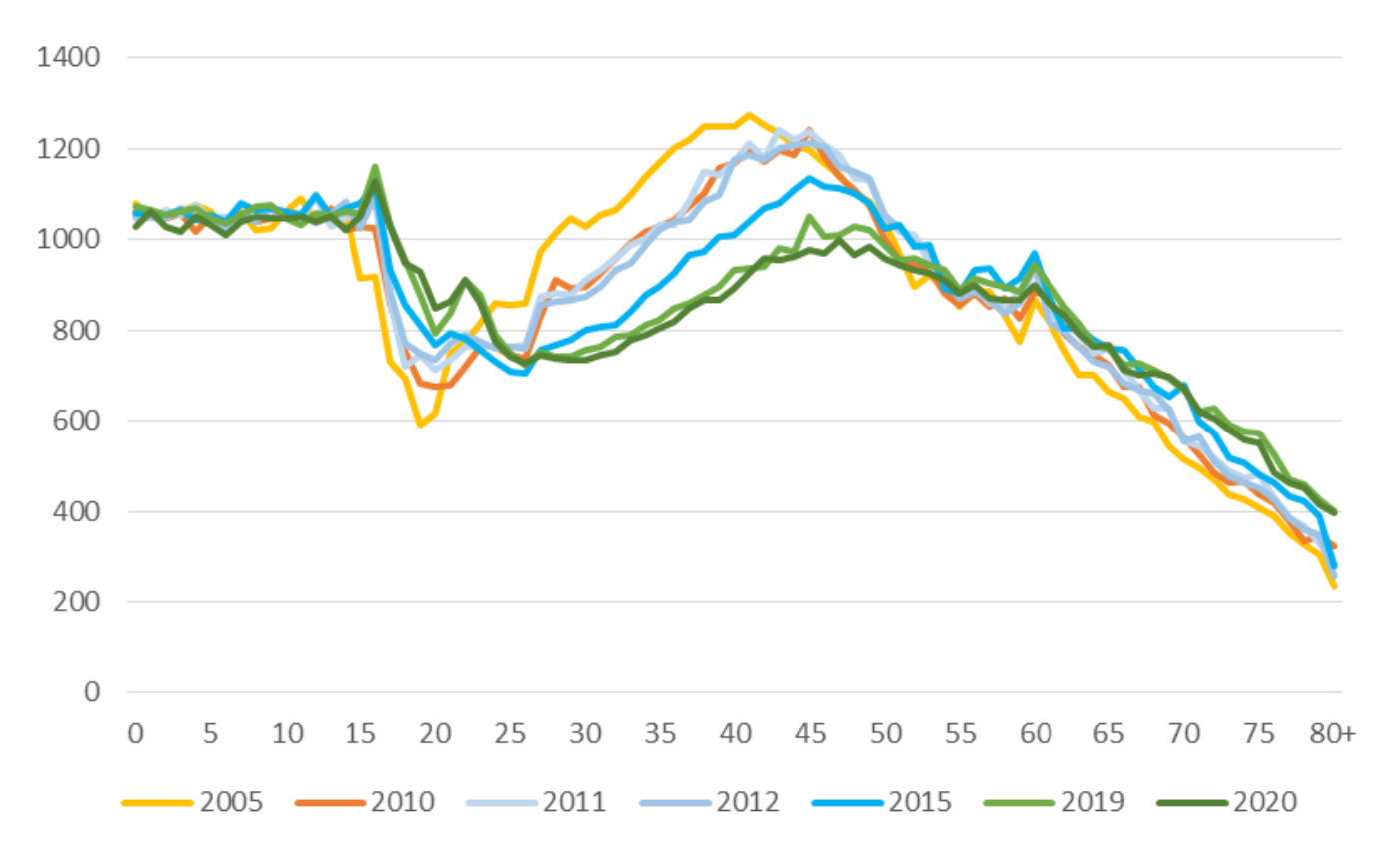

\section{Рисунок 3. Соотношение полов в потоке внутрироссийской миграции (прибытия) по 1-летним возрастным группам, число мужчин на 1000 женщин}

Источник: Расчеты автора по данным Росстата.

Соотношение полов в миграции, близкое к естественному, отмечается в детских возрастах с небольшим «пиком» преобладания мужчин к возрасту окончания основной школы. Возможно, в этом возрасте часть юношей переезжают с целью получения начального или среднего профессионального образования. В молодых трудоспособных возрастах женщины участвуют во внутристрановой миграции чаще мужчин, но к более старшим возрастам пропорции выравниваются. В средних возрастах мужчины 
преобладают в потоках миграции, далее соотношение полов в миграции близко к их соотношению в населении.

Во все годы мужчины ненамного, но активнее участвовали в межрегиональной, а женщины - во внутрирегиональной миграции (рисунок 4). Эта особенность никак не поменялась даже после более чем удвоившегося числа учтенных долговременных мигрантов после реформы системы учета в 2011 г. и изменения пропорций этих потоков в пользу межрегиональных.

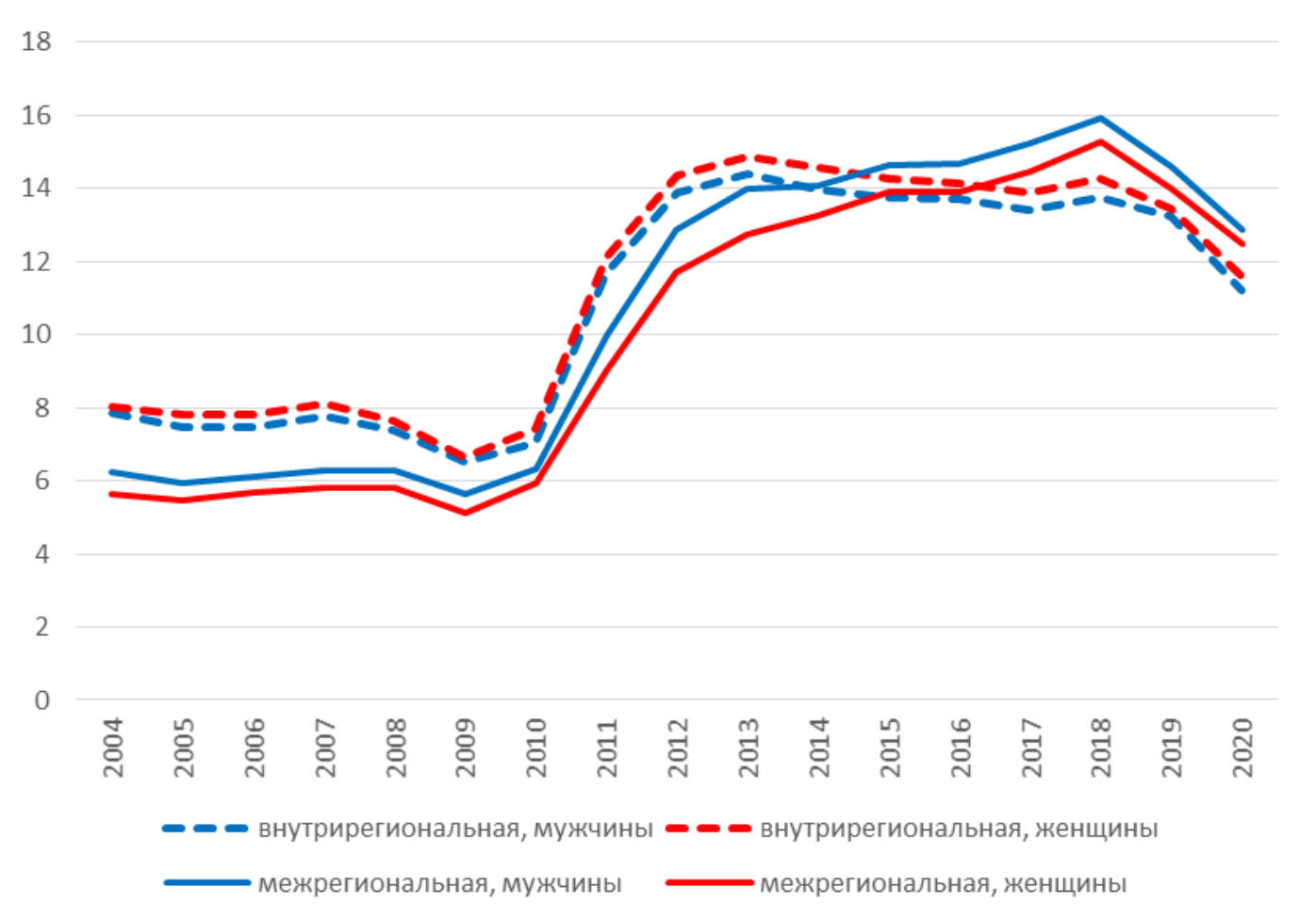

Рисунок 4. Внутрирегиональная и межрегиональная миграция по полу, на 1000 населения

Источник: Расчеты автора по данным Росстата.

По возрастам интенсивность миграции мужчин и женщин демонстрирует сходства и различия (рисунок 5). В молодых возрастах женщины явно более активны во внутрирегиональной миграции, начиная с 35-летнего возраста мужчины их опережают. Особенно явны отличия в возрасте окончания школы (18 лет): видимо, женщины чаще перемещаются в связи с получением образования и совершают эти переезды в пределах региона. Микроперепись 2015 г. показала, что женщины чаще, чем мужчины, отсутствовали в домохозяйстве по причине учебы (Микроперепись населения 2015). Но это - самые общие предположения, не позволяющие объяснить сильные различия соотношения полов в молодых возрастах. В межрегиональной миграции в этом возрасте женщины перемещаются лишь ненамного чаще. В 18-летнем возрасте в середине 2010-х годов во внутристрановой миграции участвовали $13 \%$ женщин и $11 \%$ мужчин. Неудивительно, что и пик в возрасте окончания получения профессионального образования, проявившийся после появления «псевдовозвратной» миграции (Мкртчян 2020) во второй половине 2010-х годов, также более выражен у женщин. 
25

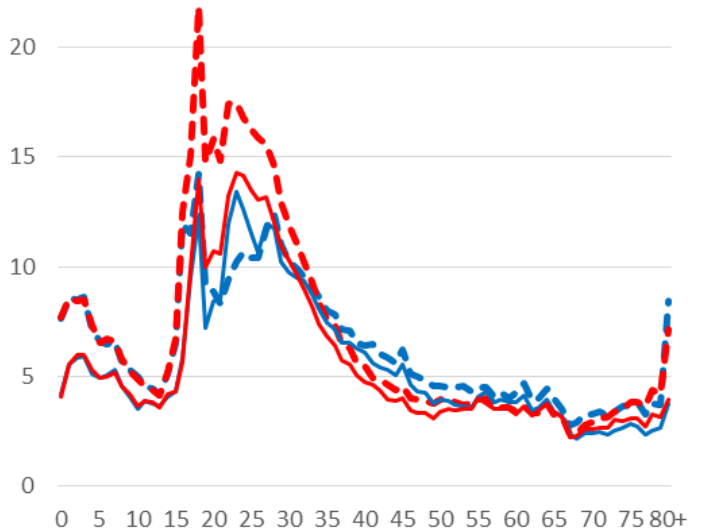

2015

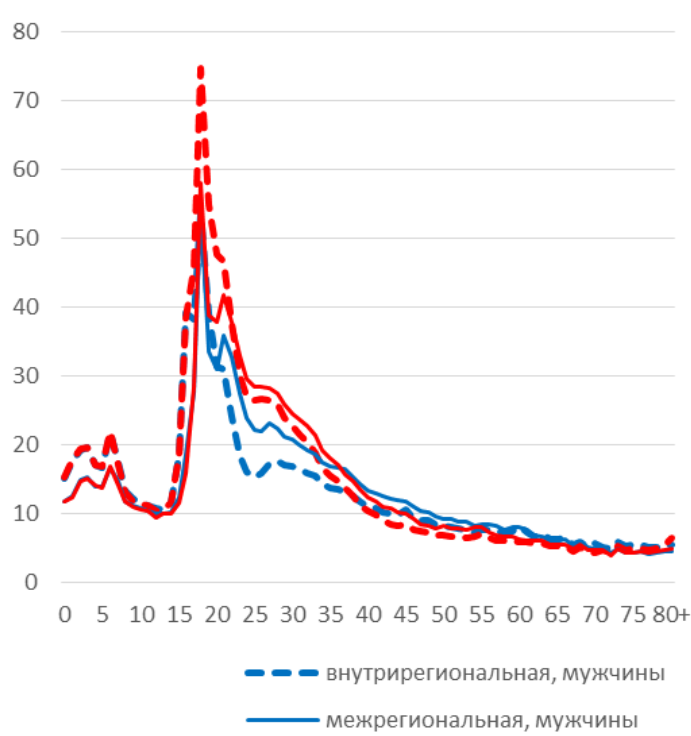

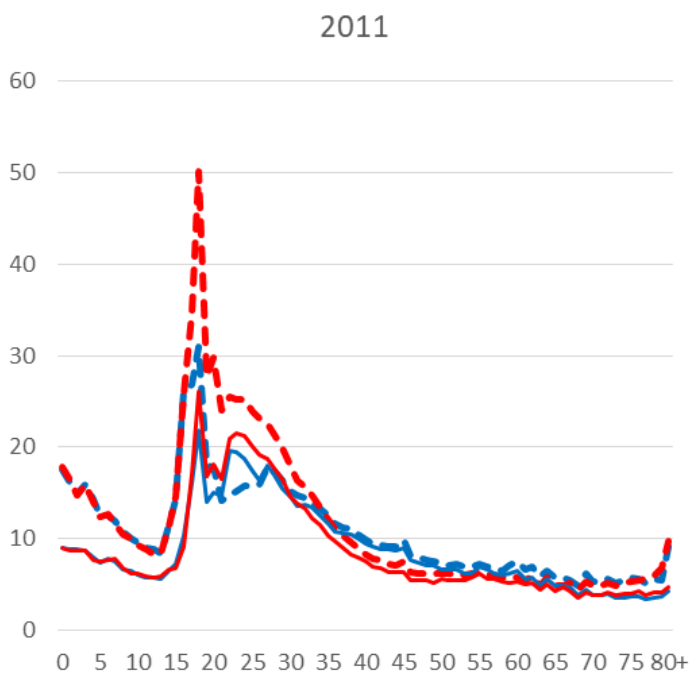

2020

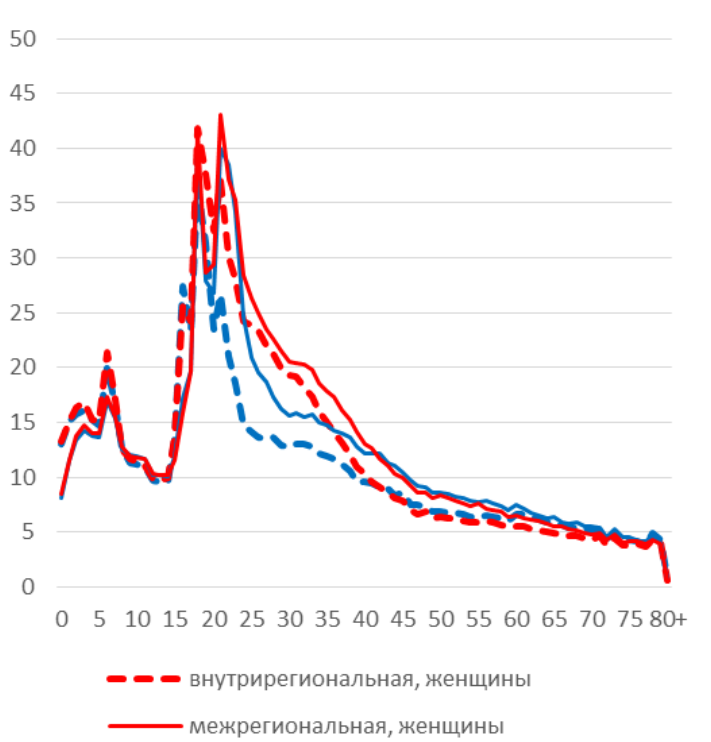

Рисунок 5. Внутрирегиональная и межрегиональная миграция по полу и возрасту, на 1000 населения

Источник: Расчеты автора по данным Росстата.

Полагаем, что большая активность женщин во внутри- и межрегиональной миграции в молодых репродуктивных возрастах объясняется:

1. их более ранним вступлением в брак и во взрослую жизнь в целом и вероятностью переездов в связи с этими событиями. Как показывают исследования внутренней миграции, возрастные профили миграции совпадают с переходом к взрослой жизни для обоих полов, но в большей степени это касается женщин (Bernard, Bell, CharlesEdwards 2014);

2. неучастием в службе по призыву (российская статистика не учитывает перемещения с этой целью). Несмотря на то, что служба в армии по призыву не имеет сейчас такого распространения, как, например, в позднесоветский период, часть молодых людей она из обычной жизни выхватывает; 
3. более частой необходимостью для женщин получать регистрацию по месту жительства и пребывания в другом регионе или населенном пункте. Регистрация может понадобиться при устройстве ребенка в дошкольное учреждение или в школу (Мкртчян и др. 2020), и если вся семья не может получить регистрацию, выбор чаще всего падает на женщину, мужчина регистрацию не оформляет;

4. тем, что в молодых трудоспособных возрастах мужчины гораздо чаще, чем женщины, участвуют во временной трудовой (вахтовой) миграции, регулярные поездки на работу оформления регистрации не требуют. Вопрос о «замещении» долговременной (переселенческой) миграции иными формами пространственной мобильности неоднократно поднимался исследователями (Моисеенко 2004; Мкртчян 2009), особенно при попытке объяснений ее спада в 1990-е годы;

5. тем, что, возможно, опыт учебной миграции, проживания в это время в другом регионе или поселении чаще ведет к последующей смене места проживания после реальной или псевдовозвратной миграции. Поэтому в возрасте 25-30 лет женщины чаще, чем мужчины, совершают переезды.

После 35-40-летнего возраста и вплоть до самых преклонных лет в обоих потоках внутренней миграции мужчины активнее. Различия не столь велики, сколь устойчивы, в том числе во времени. Полагаем, они объясняются более поздним наступлением у мужчин многих событий жизненного пути, связанных с переменной места проживания, с более частой их мобильностью после развода. Хотя известны исследования, что развод часто приводит не к смене региона проживания, а к жилой мобильности (Clark 2013). В этом возрасте женщин чаще, чем мужчин, может удерживать от миграции необходимость ухаживать за пожилыми родителями. Обращает внимание отсутствие пиков миграции, приуроченных к возрасту выхода на пенсию, которые у мужчин и женщин в России различаются.

\section{ЗАКЛЮЧЕНИЕ}

В данной статье предпринята попытка комплексного анализа особенностей распределения долговременных мигрантов в России по полу. Он показал, что возникающие диспропорции более характерны для международной миграции и они связаны с резким преобладанием в потоке мужчин в молодых и средних возрастах. На соотношение полов в этом потоке влияли изменения методики учета миграции, видимо, они вводили в статистический «оборот» категории мигрантов, существенно отличающиеся по формам и целям переезда. Репатриационная миграция, характеризовавшаяся достаточно равномерным представительством участвующих в ней мужчин и женщин, к 2010-м годам перестала доминировать в международной долговременной миграции в России. Новый состав мигрантов с явным преобладанием мужчин в трудоспособных возрастах не является нормальным, такая миграция является квазидолговременной. Она не может рассматриваться как устойчивая, что затрудняет прогнозирование миграции на средне- и долгосрочный период.

В отличие от межстрановых переселений, структура по полу внутренних мигрантов более сбалансирована, но соотношение полов существенно различается в отдельных 
возрастных группах. Но притом, что в целом они не так велики и практически не зависят от изменений методики учета, объяснить возникающие различия трудно, это требует более углубленных исследований. Для ответов на многие вопросы, выявившихся в ходе исследования, недостает детальных статистических данных, которые могли бы быть получены в ходе выборочных обследований.

Половозрастные особенности миграции в России необходимо учитывать в демографических прогнозах. Так как соотношение полов в потоках меняется достаточно динамично, структуры мигрантов должны пересматриваться так же часто, как прогнозные гипотезы. При этом в средне- и долгосрочном периоде диспропорции полов необходимо сглаживать, так как структурные особенности миграции в 2010-е годы представляются крайне неустойчивыми.

\section{ЛИТЕРАТУРА}

Вишневский А.Г. (Ред.) (2013). Население России 2010-2011. Восемнадиатыйдевятнадиатый ежегодный демографический доклад. М.: Изд. дом Высшей школы экономики.

Зайончковская Ж.А. (Ред.) (2009). Иммигранты в Москве. М.: Три квадрата

Карачурина Л.Б., Мкртчян Н.В. (2017). Межрегиональная миграция в России: возрастные особенности. Демографическое обозрение, 3(4), 47-65. URL: https://doi.org/10.17323/demreview.v3i4.3205

Кашницкий И.С. (2017). Влияние изменений в правилах учета миграции в 2011 г. на оценку интенсивности миграции молодёжи: когортно-компонентный анализ. Демографическое обозрение, 4(1), 83-97. DOI: https://doi.org/10.17323/demreview.v4i1.6989

Микроперепись населения 2015 (2015). Раздел XI. Характеристика временно отсутствующего населения. URL: https://gks.ru/free_doc/new_site/population/demo/micro-perepis/finish/micro-perepis.html

Мкртчян Н.В., Флоринская Ю.Ф., Казенин К.И. (2020). Внутренняя миграция как ресурс развития России: сочиально-экономические эффекты, издержки и ограничения (Доклад для Гайдаровского форума - 2020). М.: Издательский дом «Дело» РАНХиГС.

Мкртчян Н.В. (2009). Миграционная мобильность в России: оценки и проблемы анализа. SPERO, 11, 149-164.

Мкртчян Н.В. (2020). Проблемы в статистике внутрироссийской миграции, порожденные изменением методики учета в 2011 г. Демографическое обозрение, 7(1), 83-99. URL: https://doi.org/10.17323/demreview.v7i1.10821

Моисеенко В.М. (2004). Внутренняя миграция населения. М.: ТЭИС.

Тюрюканова Е.В. (Ред.) (2011). Женщины-мигранты из стран СНГ в России. М.: МАКСПресс.

Чудиновских О.С. (2004). О критическом состоянии учета миграции в России. Bonpocbl статистики, 10, 27-35. 
Чудиновских О.С. (2019). О пересмотре Рекомендаций ООН 1998 г. по статистике миграции в российском контексте. Вопросы статистики, 26(8), 61-76. DOI: 10.34023/2313-6383-2019-26-8-61-76.

Belanger D., Rahman M. (2013). Migrating against all the odds: International labour migration of Bangladeshi women. Current Sociology, 61(3), 356-373 DOI: $10.1177 / 0011392113484453$

Bernard A., Bell M., Charles-Edwards E. (2014). Life-course transitions and the age profile of internal migration. Population and Development Review, 40(2), 213-239. DOI: 10.1111/j.1728-4457.2014.00671.x

Clark W.A.V. (2013). Life course events and residential change: Unpacking age effects on the probability of moving. Journal of Population Research, 30(4), 319-334.

Corbett M. (2007). All kinds of potential: Women and out-migration in an Atlantic Canadian coastal community. Journal of Rural Studies, 23(4), 430-442. URL: https://doi.org/10.1016/j.jrurstud.2006.12.001

Krohnert S., Vollmer S. (2012). Gender-specific migration from eastern to Western Germany: Where have all the young women gone? International Migration, 5(50), 95- 112. DOI: 10.1111/j.1468-2435.2012.00750.x

Martin S. (2009). The effects of female out-migration on Alaska villages. Polar Geography, 32(1-2), 61-67. DOI: 10.1080/10889370903000455

Rodriguez-Vignoli J., Rowe F. (2018). Correction to: How is internal migration reshaping metropolitan populations in Latin America? A new method and new evidence. Population Studies, 72(2), 253-273. DOI: 10.1080/00324728.2017.1416155 


\title{
SEX IMBALANCES \\ IN LONG-TERM MIGRATION FLOWS IN RUSSIA
}

\author{
NIKITA MKRTCHYAN
}

\begin{abstract}
Based on Rosstat data, the distribution of long-term migration flows in Russia by gender was analyzed for the period from 2004 to 2020, taking into account differences in individual age groups. There is a clear predominance of men of working age in international migration in Russia. Disproportions grew after the change in the accounting methodology in 2007 and especially after 2011, leading not only to a change in the scale of recorded long-term migration, but also to a radical change in its sex and age structure.

By the end of the period under review, the disparities persisted, but their scale decreased significantly. Overall, intracountry migrations do not show gender disparity. However, at young ages, women are more active, especially in the flow of intraregional migration. The change in approaches to accounting for internal long-term migrants in 2011, which led to a change in their age profile, had virtually no effect on their gender distribution. Attempts have been made to explain the unequal participation of men and women in migration, but these features require further study. Given their significance, the dynamics of the age and sex composition of migrants must be taken into account in a timely manner in forecasting, along with regular adjustments of general forecast hypotheses.
\end{abstract}

Key words: population migration, migration statistics, international migration, internal migration, intraregional migration, age and sex structure of migrants.

\begin{abstract}
Nikita MKRTChyan (nmkrtchyan@hse.ru), NATIONAL ReSEARCh University Higher School of Economics, the

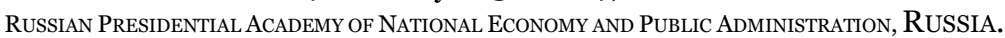

The ARTiCle WAS Written on the Basis of the RANEPA State AssignMENT RESEARCh Programme.

DATE RECEIVED : JULY 2021.

\section{REFERENCES}

Belanger D., Rahman M. (2013). Migrating against all the odds: International labour migration of Bangladeshi women. Current Sociology, 61(3), 356 - 373. DOI: 10.1177/0011392113484453

Bernard A., Bell M., Charles-Edwards E. (2014). Life-course transitions and the age profile of internal migration. Population and Development Review, 40(2), 213-239. DOI: 10.1111/j.1728-4457.2014.00671.x

Choudinovskikh O.S. (2004). O kriticheskom sostoyanii ucheta migratsii v Rossii [On the critical state of migration monitoring in Russia]. Voprosy statistiki [Issues in statistics], 10, 27-36. (In Russ.)

Choudinovskikh O.S. (2019). O peresmotre Rekomendacij OON 1998 g. po statistike migracii v rossijskom kontekste [On Revision of the UN Recommendations of Statistics of Migration (1998) an the Russian Context]. Voprosy statistiki [Issues in statistics], 8, 61-76. (In Russ.). Retrieved from https://doi.org/10.34023/2313-6383-2019-26-8-61-76.

Clark W.A.V. (2013). Life course events and residential change: Unpacking age effects on the probability of moving. Journal of Population Research, 30(4), 319-334. 
Corbett M. (2007). All kinds of potential: Women and out-migration in an Atlantic Canadian coastal community. Journal of Rural Studies, 23(4), 430-442. DOI:

https://doi.org/10.1016/j.jrurstud.2006.12.001

Karachurina L., Mkrtchyan N. (2017). Interregional Migration in Russia: Age Characteristics. Demograficheskoye Obozreniye [Demographic Review], 3(4), 47-65. DOI: https://doi.org/10.17323/demreview.v3i4.3205

Kasnitsky I. (2017). Vlijanie izmenenij v pravilah ucheta migracii v 2011 g. na ocenku intensivnosti migracii molodjozhi: kogortno-komponentnyj analiz [The Effect of the 2011 [Statistics Reform on the Estimations of Youth Migration Intensity: A Cohort-Component Analysis]. Demograficheskoe obozrenie, 4, 83-97. (In Russ.).DOI: https://doi.org/10.17323/demreview.v4i1.6989

Krohnert S., Vollmer S. (2012). Gender-specific migration from eastern to Western Germany: Where have all the young women gone? International Migration, 5(50), 95-112. DOI: 10.1111/j.1468-2435.2012.00750.x

Martin S. (2009). The effects of female out-migration on Alaska villages. Polar Geography, 32(1-2), 61-67. DOI: 10.1080/10889370903000455

Mikroperepis' naseleniya 2015 [Microcensus 2015] (2015). Razdel XI. Kharakteristika vremenno otsutstvuyushchego naseleniya [Section XI. Characteristics of the temporarily absent population]. (In Russ.). URL:

https://gks.ru/free_doc/new_site/population/demo/micro-perepis/finish/micro-perepis.html

Mkrtchyan N. (2009). Migratsionnaya mobil'nost' v Rossii: otsenki i problemy analiza [Migration mobility in Russia: estimates and problems of analysis]. SPERO, 11, 149-164. (In Russ.).

Mkrtchyan N. (2020). Problemy v statistike vnutrirossiyskoy migratsii, porozhdennyye izmeneniyem metodiki ucheta v $2011 \mathrm{~g}$. [Problems in the Statistics of Internal Russian Migration Caused by Changes in Accounting Methods in 2011]. Demograficheskoe obozrenie, 7(1), 83-99. (In Russ.). DOI: https://doi.org/10.17323/demreview.v7i1.10821

Mkrtchyan N.V., Florinskaya Y.F., Kazenin K.I. (2020). Vnutrennyaya migratsiya kak resurs razvitiya Rossii: sotsial 'no-ekonomicheskiye effekty, izderzhki i ogranicheniya [Internal migration as a resource for the development of Russia. Socio-economic effects, costs and constraints] (Doklad dlya Gaydarovskogo foruma - 2020). Moscow: Izdatel'skiy dom «Delo» RANKhiGS. (In Russ.).

Moiseenco V.M. (2004). Vnutrennyaya migratsiya naseleniya [Internal migration of the population]. Moscow: TEIS. (In Russ.).

Rodriguez-Vignoli J., Rowe F. (2018). Correction to: How is internal migration reshaping metropolitan populations in Latin America? A new method and new evidence. Population Studies, 72(2), 253-273. DOI: 10.1080/00324728.2017.1416155

Tjurjukanova E. (Ed.) (2011). Zhenshchiny-migranty iz stran SNG v Rossii [Women migrants from CIS countries in Russia]. Moscow: MAKS-Press. (In Russ.).

Vishnevsky A.G. (Ed.) (2013). Naseleniye Rossii 2010-2011. Vosemnadtsatyy-devyatnadtsatyy ezhegodnyy demograficheskiy doklad [Population of Russia 2010-2011. Eighteenth to Nineteenth Annual Demographic Report]. Moscow: Izd. dom Vysshey shkoly ekonomiki. (In Russ.).

Zayonchkovskaya Z. (Ed.) (2009). Immigranty v Moskve [Immigrants in Moscow]. Moscow: Tri kvadrata. (In Russ.). 